\title{
POLÍTICAS PÚBLICAS COMO TEMA DE PRODUÇÃO TEXTUAL: UMA ANÁLISE BAKHTINIANA DE CINCO EDIÇÕES DA PROVA DE REDAÇÃO DO ENEM
}

\author{
Renato Cabral Rezende* \\ Universidade de Brasília \\ Instituto de Letras \\ Departamento de Linguística, Português e Línguas Clássicas \\ Brasília, DF, Brasil
}

\begin{abstract}
Resumo: Este trabalho tem por objetivo analisar a construção do tema de cinco edições da prova de redação do ENEM que tiveram como objeto de sentido (BAKHTIN, 2000) infância elou juventude. Almeja discutir construção temática da prova de redação a partir da relação entre o conceito de tema, segundo Bakhtin (2000) e Bakhtin/Volochinov (2004), e os conceitos de políticas públicas e ciclo de políticas públicas, do campo da administração pública, segundo Secchi (2014). A análise mostra um enfoque sobre como o Estado pode voltar-se para a discussão elou solução de problemas que possam ferir direitos da infância $e$ da adolescência. Conclui reafirmando a necessidade de leitura da prova de redação do ENEM como um incentivo ao ensino de leitura e produção textual por meio de projetos interdisciplinares na/para a discussão de políticas públicas.
\end{abstract}

Palavras-chave: Tema. Produção textual. Políticas públicas. ENEM.

1 CONSIDERAÇÕES INICIAIS

Este trabalho resulta de uma inquietação com relação à prova de redação do Exame Nacional do Ensino Médio (ENEM), a saber, como ocorre a construção dos temas deste certame, quais são suas características, qual é a interlocução que ela propõe. Tenho como ponto de partida a hipótese de que uma compreensão mais clara dos temas - que não apenas o genérico "um tema de ordem social, científica, cultural ou política" - é fundamental para fortalecer as contribuições ao ensino de língua portuguesa na escola média pública, pois uma política pública da envergadura do ENEM pode ter impactos no ensino de leitura e produção textual no país.

Já é truísmo falar das dimensões demográfica, territorial, econômica e de biodiversidade do Brasil e o impacto que podem ter na construção de uma sociedade aberta e plural, demandando de nós reflexão acerca de instrumentos que formulam, estruturam e/ou avaliam políticas públicas vivenciadas na relação entre Estado, indivíduos e tecido social. Aceita essa premissa geral, e proposto o recorte, defenderei neste trabalho que os temas (BAKHTIN/VOLOCHINOV, 2004) construídos pela prova de redação do ENEM têm se desenvolvido no sentido de incentivar o/a candidato/a a refletir sobre políticas públicas de alcance nacional já implementadas ou a serem

\footnotetext{
* Professor Adjunto da Universidade de Brasília (UnB), Departamento de Linguística, Português e Línguas Clássicas (LIP). E-mail: renato.rcr@gmail.com
} 
implementadas, bem como os diálogos possíveis com outras nações com relação às suas políticas (tema da prova de 2014, por exemplo, como veremos abaixo).

Analisaremos neste trabalho as edições de 1998, 1999, 2000, 2005 e 2014 da prova. A pergunta que me norteia é: pode-se afirmar que a prova de redação do ENEM apresenta uma peculiaridade ao promover a interlocução sobre problemas públicos nacionais e/ou internacionais sendo que ela poderia trazer algum impacto no ensino de leitura e produção textual no ensino médio? Defendo que a prova de redação do ENEM possui uma peculiaridade se comparada à prova de produção textual de outros exames de ingresso no ensino superior. Essa peculiaridade é a de que ela convoca os/as jovens para o debate de problemas públicos nacionais ou internacionais contemporâneos, motivando reflexão sobre políticas públicas que visam a sanar os problemas em questão. O texto está organizado da seguinte forma: na seção 2, abordarei o que é o ENEM quando pensado como política pública em sua abrangência quantitativa e a oportunidade que isso pode significar na reflexão sobre os temas de sua prova de redação; na seção 3 , focarei especificamente a prova de redação e procederei à análise dos temas das edições supracitada do certame; na seção final, teço comentários sem, no entanto, pretender esgotar a discussão.

\section{ASPECTOS QUANTITATIVOS E QUALITATIVOS DO ENEM ENQUANTO POLÍTICA PÚBLICA}

O Exame Nacional do Ensino Médio (ENEM) foi instituído pela portaria $n^{\circ}$ 438/1998, do Ministério da Educação e da Cultura (MEC), há quase duas décadas. Foi concebido na esteira dos princípios da Lei de Diretrizes e Bases 9.394/1996, que prevê, em seu Art. 35, II, a formação no ensino médio para o mercado de trabalho e para a atuação cidadã, e da Lei no 10.172/2001 (o último Plano Nacional de Educação, PNE), tendo como objetivo atuar como mecanismo de avaliação educacional pelo governo federal.

Sua finalidade seria a de oferecer aos estudantes uma autoavaliação de desempenho que, assim, seria um parâmetro para "Art. $1^{\circ}$ : [...] II - criar referência nacional para os egressos de qualquer das modalidades do ensino médio; III - fornecer subsídios às diferentes modalidades de acesso à educação superior; IV - constituir-se em modalidade de acesso a cursos profissionalizantes pós-médio" (INEP, 1998). Acerca das finalidades do exame, Quinalia et al. (2013, p. 67) informam que o ENEM foi concebido para ser um instrumento de avaliação de competências, definidas, no seu documento-base, como as "modalidades estruturais da inteligência, ou melhor, ações e operações que utilizamos para estabelecer relações com e entre objetos, situações, fenômenos e pessoas que desejamos conhecer" (BRASIL, 1999, p. 11). Foi também concebido para ser um instrumento de avaliação de habilidades, que, por decorrerem das competências, constituem a dimensão do "saber-fazer", o saber lidar com situações-problema com vistas a, a partir da manipulação de conceitos trabalhados no ensino, buscar soluções para tais situações. Quinalia et al. (2013) entendem, desta forma - e com razão -, que, porque o exame objetiva ser um instrumento de medição e avaliação, por parte do Estado, de competências e habilidades do jovem para sua inserção no mercado de trabalho e para a prática da cidadania é que se pode afirmar que o ENEM é uma política pública. 
Ao longo de seus quase vinte anos, no entanto, pode-se constatar que o ENEM não teve um objetivo fixo. Foi, gradualmente, sendo construído de um exame voluntário de aferição de resultados, em 1998, a uma política pública de avaliação de conhecimentos para ingresso no ensino superior brasileiro e, atualmente - não sem contestação - de certificação de conclusão do ensino médio. No ano de 2002, com a portaria do MEC $\mathrm{n}^{\circ}$ $111 / 2002$, o exame tornou-se uma modalidade complementar aos exames de acesso aos cursos profissionalizantes e ao Ensino Superior. Quatro anos mais tarde, em 2006, nova portaria, agora a de $n^{0} 7 / 2006$, dá nova redação aos objetivos do exame, sendo a redação do objetivo IV: "possibilitar a participação e criar condições de acesso a programas governamentais" (BRASIL, 2006). Em 2005 havia sido criado o Programa Universidade para Todos (PROUNI), programa para o qual a realização do ENEM tornou-se obrigatória.

Para uma visada quantitativa que correlacione o número de inscritos/as às transformações do ENEM, vejamos a tabela 1 abaixo:

Tabela 1 - Inscrições no ENEM e variação percentual comparativa entre 1998 e 2004

\begin{tabular}{l|r|r}
\hline Ano & Quantidade de inscrições & Variação Percentual \\
\hline 1998 & 157.221 & - \\
\hline 1999 & 346.953 & crescimento de $120,60 \%$ \\
\hline 2000 & 390.180 & crescimento de $12,40 \%$ \\
\hline 2001 & 1.200 .883 & crescimento de 207,70\% \\
\hline 2003 & 1.318 .820 & crescimento de $9,82 \%$ \\
\hline 2004 & 1.882 .393 & crescimento de $42,70 \%$ \\
\hline $\begin{array}{l}2005 \\
\text { (criação e implementação do PROUNI) }\end{array}$ & 1.522 .316 & retração de $19,12 \%$ \\
\hline
\end{tabular}

Fonte: o autor.

Nova modificação no exame vem à tona em 2009. Naquele ano, o ENEM experimentou uma grande reformulação em sua utilização, tornando-se mecanismo de seleção única das universidades federais a partir de proposta encaminhada pelo MEC à Associação Nacional dos Dirigentes das Instituições Federais de Ensino (ANDIFES) ${ }^{1}$. Essa reformulação foi um salto qualitativo em termos de acesso, via ENEM, ao ensino superior público. Se, em 2005, o ENEM foi o instrumento de ingresso maciço no ensino superior privado, composto, em sua grande maioria, por estudantes egressos do ensino médio público, a partir de 2009 ele passou a ser também o amplo mecanismo de ingresso no ensino superior público, composto, em sua grande maioria, por estudantes da escola média privada. O ENEM per se não lidou (ou lida) diretamente com a necessidade de reparação da injustiça estrutural, em nossa sociedade, do ingresso no ensino superior público de jovens cujos pais pagaram por sua educação básica, enquanto aqueles/as que tiveram, majoritariamente, educação básica na escola pública, são os/as que compõem o corpo discente das instituições privadas.

1 Disponível em: 〈http://download.inep.gov.br/download/imprensa/Andifes_Proposta_Inep-MEC.pdf〉. Acesso em: 27 jun. 2017. 
Mesmo não revertendo o injusto modelo de participação da juventude no ensino superior brasileiro, o ENEM não deixou de contribuir para a democratização do acesso ao ensino superior público. Antes de 2009, faziam exame para ingresso em uma Instituição Federal de Ensino Superior (IFES) apenas os/as que podiam pagar por mais de uma taxa de inscrição no vestibular. Por ser o exame de dimensão nacional mais consolidado, agora em um modelo unificado, de $2009 \mathrm{em}$ diante a/o candidato/a passou a ser "alocado/a" segundo sua pontuação na prova. Com base apenas em sua nota do ENEM, ela/ele poderia escolher em qual instituição federal de ensino superior desejaria dar seguimento a seus estudos. Foi a partir deste momento, em especial, frisa Oliveira (2013, p. 2), que, além de exame único para ingresso no ensino superior, o ENEM tornouse também fonte para estudos sobre a educação brasileira e para referência com vistas ao aperfeiçoamento do currículo do Ensino Médio.

Na tabela 2 seguimos com a visada quantitativa que correlaciona o número de inscritos às transformações do ENEM:

Tabela 2 - Inscrições no ENEM e variação percentual comparativa entre 2006 e 2015

\begin{tabular}{l|r|r}
\hline Ano & Quantidade de inscrições & Variação Percentual \\
\hline 2006 & 3.731 .925 & crescimento de $24,40 \%$ \\
\hline 2007 & 3.568 .592 & retração de $4,370 \%$ \\
\hline 2008 & 4.018 .050 & crescimento de $12,50 \%$ \\
\hline novo ENEM (muitas IFES passam a adotá-lo) & 4.147 .527 & crescimento de 3,22\% \\
\hline 2010 & & \\
\hline 2011 & 4.611 .441 & crescimento de $11,10 \%$ \\
\hline 2013 & 6.221 .697 & crescimento de $34,90 \%$ \\
\hline 2014 & 6.497 .466 & crescimento de $4,43 \%$ \\
\hline 2015 & 7.173 .574 & crescimento de $10,40 \%$ \\
\hline
\end{tabular}

Fonte: o autor.

Nota-se que o crescimento do número de inscritos/as na edição de 2009 é abaixo do das edições anteriores. A proposta do novo ENEM surge com o exame completamente consolidado no país. Observando-se ambas as tabelas, não é pouco significativo o crescimento de inscrições no ENEM ao longo de sua existência. Com exceção dos anos de 2004, 2007 e 2015, em que houve retração de inscritos/as, em todos os demais anos observa-se sempre crescimento, destacando-se os anos de 2005, com o PROUNI e 2011, 2014, anos em que também houve crescimento elevado. O que se pode constatar, com base nas tabelas 1 e 2, é que o ENEM firmou-se, em seus quase vinte anos, como um esforço, de dimensão nacional, de instrumento de seleção e distribuição (por meio do Sisu) de estudantes no ensino superior público e privado no país. Sendo o ENEM uma tentativa de minimizar o reconhecido "gargalo" ao final do ensino médio, os elevados números devem ser vistos com otimismo, a prova de redação do ENEM está "na boca do povo", é motivo de conversa nos lares, nas filas de banco e de supermercado; mas também com cautela: que compreensão estudantes e seus/suas professores/as têm dos temas da prova de redação do ENEM? Como fazer para que compreendam a maneira como a prova é estruturada? 
Intimamente à cautela, porém, e paradoxalmente, estes números também devem ser vistos como uma janela de oportunidade para educação em/sobre políticas públicas no ensino de língua portuguesa, com vistas ao ingresso no ensino superior. A prova de redação do ENEM vale 50\% do valor da nota total do exame. De nada adiantará a janela de oportunidade se a cautela for tomada como sinônimo de descrédito do potencial do estudante; tampouco valerá a cautela se essa janela de oportunidade para educação em/sobre políticas públicas não for devidamente transformada em objeto de ensinoaprendizagem. Escrever se aprende escrevendo: para conhecermos o real estado da produção textual dissertativo-argumentativa de estudantes recém-ingressos/as nas universidades no país, são necessárias pesquisas de grande envergadura, de natureza qualitativa e quantitativa. São elas que poderão apontar caminhos sobre o que melhorar nas práticas de ensino-aprendizagem em produção textual.

\title{
3 A PROVA DE REDAÇÃO DO ENEM QUANTO AO ASSUNTO "INFÂNCIA E/OU JUVENTUDE": A QUE VEM, AFINAL? 3.1 COMPARANDO AS PROVAS DE 1998, 1999 E 2000
}

É do conhecimento público, divulgado no manual do candidato (BRASIL, 2013, p. 7), que a prova de redação do ENEM consiste em:

\begin{abstract}
Produção de um texto em prosa, do tipo dissertativo-argumentativo, sobre um tema de ordem social, científica, cultural ou política. Os aspectos a serem avaliados relacionam-se às "competências" que você deve ter desenvolvido durante os anos de escolaridade. Nessa redação, você deverá defender uma tese, uma opinião a respeito do tema proposto, apoiada em argumentos consistentes estruturados de forma coerente e coesa, de modo a formar uma unidade textual. Seu texto deverá ser redigido de acordo com a norma padrão da Língua Portuguesa e, finalmente, apresentar uma proposta de intervenção social que respeite os direitos humanos.
\end{abstract}

A hipótese que defendo é a de que a prova de redação do ENEM não é apenas o que se lê no manual do candidato. Essa elaboração de uma tese para que o texto seja apoiado em argumentos consistentes de forma coerente e coesa, formando uma unidade textual, devendo também, seja ao longo do texto, seja ao final dele, haver a proposição de uma solução para o problema apresentado, não se resume a uma mera discussão de "ordem social, científica, cultural ou política". Ela é muito mais e isso precisa ser ensinado aos/às estudantes.

Como a maioria das democracias liberais modernas, o Brasil é uma sociedade organizada sob a forma de Estado, e isso é decisivo na forma como vivemos as questões da vida coletiva. Minha leitura é a de que o recorte temático proposto para a produção textual é o da reflexão sobre os conflitos e/ou as convergências entre três lugares de agência social: (i) Estado; (ii) sociedade (organizada sob a forma de ONG's, empresas privadas, etc.) e (iii) indivíduos (tomados unitariamente ou em relação à família), havendo destaque para o papel do Estado acerca de problemas que ensejam ou que já são mediados por políticas públicas do Brasil contemporâneo. Da prova de produção textual do ENEM a partir de 2000, pode-se dizer que tem sido assente - ora de maneira mais explícita, ora 
menos - nessa tríade, sendo muito mais do que uma escolha aleatória de uma "questão social". Há uma contextualização que mais ou menos contempla essa relação triangular "Estado-sociedade-indivíduo", representada pela Figura 1:

\title{
Figura 1 - Relação triangular constitutiva dos temas da prova de redação do ENEM
}

\author{
Estado (Poderes Executivo [Administração Direta ou Indireta], Legislativo e Judiciário)
}

Indivíduos e Empresas

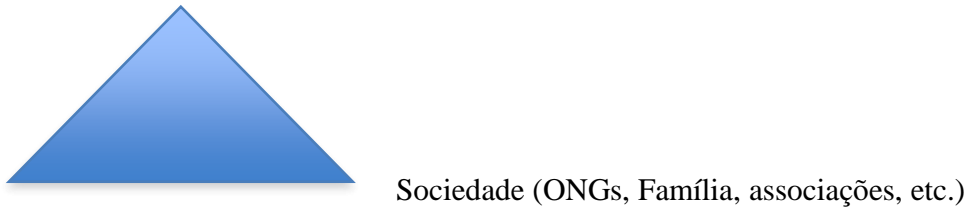

Informa-nos Bakhtin (2000) que os gêneros do discurso jamais estão dissociados das esferas de atividade onde circulam. Essa afirmação, certamente, vale também para o gênero dissertativo argumentativo - que é exatamente o gênero que estamos abordando. A realidade de todo texto, que nada mais é do que instanciações dos gêneros, é a do vínculo orgânico entre sua estrutura composicional, o estilo em que é escrito, e o recorte/tratamento na abordagem como o objeto de sentido (o "assunto") é tratado, o tema, para atender às necessidades comunicativas do intuito do autor e dos espaços sociais onde os gêneros circulam:

Teoricamente o objeto [de sentido] é inesgotável, porém, quando se torna tema de um enunciado (de uma obra científica, por exemplo), recebe um acabamento relativo, em condições determinadas, em função de uma dada abordagem do problema, do material, dos objetivos por atingir, ou seja, desde o início ele estará dentro dos limites de um intuito definido pelo autor (BAKHTIN, 2000, p. 300, grifos do autor).

Como se pode observar, o tema, para Bakhtin, é o tratamento textual-discursivo e multimodal que um fato, ou conjunto de fatos, um fenômeno natural ou social, ou atores sociais recebem no interior de um gênero para que a produção de textos daquele gênero produza uma interlocução social específica com os/as leitoras/es em potencial em determinados espaços sociais.

Comecemos analisando a prova de redação do ano $2000^{2}$ para observar como a construção temática da prova de redação do ENEM ocorre:

\footnotetext{
2 Disponível em: <http://download.inep.gov.br/educacao_basica/enem/provas/2000/2000_amarela.pdf>.
} Acesso em: 15 maio 2017. 
Figura 2 - Prova de redação do ENEM do ano 2000

Enerm 2000

REDAÇÃO

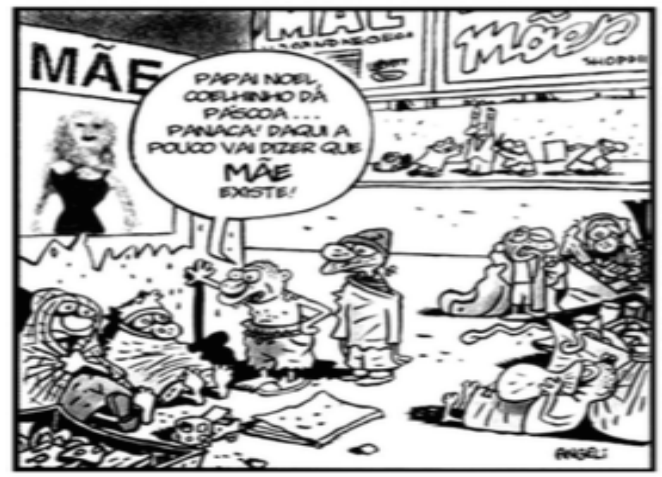

(Angeli, Folla de S. Pawlo, 14.05.2000)

(...) Esquina da Avenida Desembargador Santos Neves com Rua José Teixeira, na Praia do Canto, área nobre de Vitória. A.J., 13 anos, morador de Cariacica, tenta ganhar algum trocado vendendo balas para os motoristas. (...) "Venho para a rua desde os 12 anos. Näo gasto de trabalhar aqui, mas nảo tem outro jeito. Quero ser mecânico

A Gazesa, Vinória (ES), 9 de junho de 2000.
"É dever da famílla, da socledade e do Estado assegurar à criança $e$ ao adolescente, com absoluta prlorldade, o direlto à saúde, à allmentaçāo, à cultura, à dlgnidade, ao respeito, à llberdade e à convivêncla familliar e comunitária, além de colocálos a salvo de toda forma de negligência, dlscriminaçāo, exploraçāo, crueldade e opressāo". Artigo 227, Concrituicato da Repriblica Federativa do Braril

Entender a infância marêinal significa entender porque um menino vai para a rua e nào à escola. Essa e. em essência, a diferença entre o garoto que está dentro do carro, de vidros fechados, $e$ aquele que se aproxima do carro para vender chiclete ou pedir esmola. E essa é a diferença entre um país desenvolvido e um país de Terceiro Mundo.

Com base na leitura da charge, do artigo da Constituição, do depoimento de A.J. e do trecho đo livro 0 cidadảo đe papel, redija um texto em prosa, do tipo dissertativo-argumentativo, sobre o tema: Direitos da criança e do adolescente: como enfrentar esse desafio nacional?

Ao desenvolver o tema proposto, procure utilizar os conhecimentos adquiridos e as reflexōes feitas ao longo de sua formaçăo. Selecione, organize e relacione argumentos, fatos e opiniōes para defender o seu ponto de vista, elaboranđo propostas para a soluçảo do problema discutido em seu texto.

Fonte: ENEM 2000.

O tema desta que foi a terceira edição do exame foi "Direitos da criança e do adolescente: como enfrentar esse desafio nacional?". Há na prova quatro textos motivadores. Proponho que sejam lidos como se estivessem em duas colunas verticais: 1 ) uma charge do cartunista Angeli, publicada em maio daquele mesmo ano no jornal Folha de S. Paulo, que tem circulação nacional, em que crianças em situação de rua ridicularizam a existência das mães (tal como não existem outros seres que, como as mães, podem estar ligados à agenda do calendário do consumismo); 2) exatamente abaixo da charge, lê-se o fragmento de uma notícia sobre um garoto que vende balas no semáforo, notícia esta que, como a charge, fora publicada naquele ano, mas no jornal A Gazeta, do Espírito Santo, menos de um mês após a publicação da charge; compondo a coluna à direita, 3) um fragmento do Art. 227 da Constituição Federal de 1988, que afirma que é dever da família, da sociedade e do Estado assegurar direitos à criança, protegendo-a de situações que a violentam; 4) abaixo do texto constitucional, uma passagem da obra Cidadão de Papel, de Gilberto Dimenstein, em que o autor define infância marginal.

A própria disposição dos textos motivadores já é um primeiro indício da construção temática, entendida como o tratamento textual-discursivo de um fato no interior de um gênero (no caso, o gênero prova de concurso público) para que a produção de textos 
daquele gênero produza uma interlocução social específica. Os textos 1 e 2 compõem uma mesma coluna visual à esquerda, coluna esta que pode ser entendida como sendo da dimensão daquilo que é, isto é, do plano do real (ainda que um deles seja ficcional). Ambos são exemplos que vocalizam a voz dos sujeitos abandonados: se em 1 as crianças estão em abandono pelo Estado e por toda a sociedade a ponto de desdenharem da existência do ente "mãe" e, por ilação, de família; em 2 o abandono se dá pelo Estado: embora em condição não tão miserável como em 1, o garoto do texto 2 vivencia, porém, o trabalho infantil. Essa vocalização acontece justamente no espaço social que, por definição, deve produzir conhecimento sobre a sociedade e dar voz a seus atores, o domínio discursivo jornalístico. Em contrapartida, a coluna da direita, onde encontramse os textos 3 e 4, pode ser entendida como da dimensão do como deveria ser, uma espécie de plano do ideal: o texto 3 é o ideal de como devem agir o Estado e toda a sociedade (o que inclui as famílias) vis-à-vis a infância. É o próprio Estado, por meio de seu documento fundador, que vocaliza; já o texto 4 analisa os textos da coluna à esquerda, conceituando o que se leu neles, e apontando, por uma negação implícita, o que deveria ser uma infância ideal; é a vocalização de uma racionalidade crítico-analítica.

Vimos que, para Bakhtin (2000), o tema, isto é, o recorte/tratamento na abordagem de um objeto de sentido (um "assunto"), é um dos aspectos fundamentais da constituição de um gênero discursivo. Sem tema, não há gênero discursivo e, sem gênero, não há interlocução social. Ainda segundo o autor (BAKHTIN/VOLOCHINOV, 2004, p. 131), falar em tema é falar na "investigação da significação contextual de uma dada palavra nas condições de enunciação concreta". As palavras "direitos" e "desafios" dão concretude temática ao enunciado "Direitos da criança e do adolescente: como enfrentar esse desafio nacional?" se e somente se nós pensarmos esta afirmação na realidade histórica, concreta e real, apresentada pelos textos motivadores da prova: crianças que duvidam da existência do ente mãe; o Estado que falha ao cumprir seu dever, resultando, no país, na existência de uma infância marginal. Os desafios são o que o candidato deve analisar e discutir, propondo-lhes soluções, para que sejam alcançados os direitos.

É por isso que Bakhtin/Volochinov (2004) afirma que o tema é o sentido da enunciação completa, a saber, a "expressão de uma situação histórica concreta que deu origem à enunciação" (BAKHTIN/VOLOCHINOV, 2004, p. 128), no caso, o enunciado presente na prova: "Direitos da criança e do adolescente: como enfrentar esse desafio nacional"? O tema é o sentido histórico de todo enunciado linguístico quando analisado em sua plena realização contextual.

Prossegue o autor: o tema "é concreto, tão concreto como o instante histórico ao qual ele pertence. "Somente a enunciação tomada em toda a sua amplitude concreta, como fenômeno histórico, possui tema” (BAKHTIN/VOLOCHINOV, 2004, p. 129). É exatamente neste sentido - e com essas palavras, que tomo emprestadas do autor - que defendo que os temas da prova de redação do ENEM são a expressão de uma condição histórica de necessidade de discussão de soluções/políticas públicas para problemas históricos e concretos da realidade brasileira e/ou mundial. O triângulo proposto na Figura 1 nada mais é do que uma tentativa de proposição teórica (em diálogo com o campo da ciência política) e visualização pedagógica disso. 
Não gratuitamente - trata-se de fatos que caracterizam fortemente o estado de carência inerente à parte da infância e juventude brasileiras -, como se pode observar, três vozes sociais se fazem mais nítidas no tema da edição de 2000: a do Estado que abandona, mas que vocaliza o que deve ser o ideal de infância; a dos indivíduos que são abandonados (as crianças), cujas vozes são veiculadas no espaço por excelência (ao menos em tese) do debate público, a imprensa; e a de um indivíduo vinculado à sociedade, que conceitua o problema original, a infância marginal. Fica patente, portanto, essa relação triangular "Estado-sociedade-indivíduo", tal como representado na Imagem 1, na prova de 2000, como base da "amplitude concreta" que leva à formulação do nome tema, no sentido que Bakhtin/Volochinov (2004) atribui ao termo. A prova de redação do ENEM daquele ano foi a primeira pensada para fomentar e/ou avaliar a inserção do/a estudante em um debate público em que estas três dimensões de atores sociais, basilares a uma sociedade organizada sob a forma de Estado, mais especificamente, como democracia liberal, se faziam presentes, tendo como foco a promoção de reflexão crítica, neste processo, das relações entre os atores sociais localizados nos três vértices do triângulo da Figura 1.

Não foi o caso da primeira edição do exame, em 1998³. A subsequente, em 19994, também não previa essa relação com nitidez. Vejamo-las:

Figura 3 - Prova de redação do ENEM do ano de 1998

\begin{tabular}{ll|}
\hline \hline OQué Ó QuéÉ \\
REDAÇÃO \\
(...) \\
Viver \\
e não ter a vergonha de ser feliz \\
Cantar e cantar e cantar \\
a beleza de ser um eterno aprendiz \\
Eu sei \\
que a vida devia ser bem melhor \\
e será \\
Mas isso não impede que eu repita \\
É bonita, é bonita e é bonita \\
(...)
\end{tabular}
expressão do texto motivador "O Que É O Que É".

Dê um título à sua redação, que deverá ser apresentada a tinta e desenvolvida na folha anexa ao Cartẫo-Resposta. Você poderá utilizar a última página deste Caderno de Questōes para rascunho.

Fonte: ENEM 1998

\footnotetext{
${ }^{3}$ Disponível em: < http://download.inep.gov.br/educacao_basica/enem/provas/1998/1998_amarela.pdf >. Acesso em: 15 maio 2017.

${ }^{4}$ Disponível em: < http://download.inep.gov.br/educacao_basica/enem/provas/1999/1999_amarela.pdf >. Acesso em: 15 maio 2017.
} 
Na prova de 1998, o tema foi nomeado como "Viver e aprender", tendo como texto motivador o refrão da canção "O que é o que é", de Gonzaguinha. Não se pode observar nela qualquer indício da tríade Estado-sociedade-indivíduos na promoção do debate de um problema público (o foco é apenas na dimensão do indivíduo). Não há na construção do tema um problema público concreto, vivenciado por toda a população brasileira, ou, pelo menos, pela juventude brasileira. O tema é quiçá muito mais da dimensão individual do que coletiva. Não há proposta de intervenção para um problema público justamente porque não há problema público em discussão.

$\mathrm{Na}$ edição do ano seguinte (ver Figura 4 abaixo), o tema da prova de redação do ENEM descola-se de como a proposta do ano anterior fora construída. Intitulado "Cidadania e participação social", o tema foi construído com base em cinco textos motivadores, o que diferencia notoriamente a edição de 1999 da edição anterior do exame. O primeiro é uma narrativa em quadrinhos de Henfil, publicada na obra Fradim, do mesmo autor, em 1997. À personagem Graúna - que repousa sobre um cacto -, outro pássaro diz, no primeiro quadrinho, que ela é incapaz de voar. No segundo, complementa: "você é da geração de graúnas que já nasceu sem asas", dando-lhe as costas no terceiro quadrinho. No penúltimo quadro, Graúna abre suas asas, que se revelam bastante grandes, plenamente capazes de fazê-la voar, e seus olhos brilham. No último, ela afirma: "a juventude é uma caixinha de segredos".

O segundo texto é um fragmento de uma notícia do jornal Folha de S. Paulo, intitulada "Para quem se revolta e quer agir", e publicada em novembro do ano anterior. A notícia informa a respeito do encontro Vem ser cidadão, que reuniu, no Paraná, 380 jovens de 13 estados do país para trocarem experiências sobre o protagonismo juvenil. Ela assinala que o jovem não "precisa de adulto para encontrar o seu lugar e sua forma de intervir na sociedade", ou seja, não precisa de tutela para ser protagonista de ações sociais. Assim como já vimos com a edição do ano subsequente (ano 2000), há um texto verbal que representa o que é tematizado em um texto multimodal ficcional. Os três últimos textos motivadores são fragmentos de depoimentos ao jornal de jovens que participaram do encontro, dando concretude ao que é apresentado na tirinha. O primeiro, de MG, afirma que o comodismo face à injustiça social é um problema. No segundo, do PR, a/o depoente relaciona comodismo e necessidade de mobilização (para superá-lo). No último, do AM, o/a depoente fala sobre a necessidade de pró-atividade da juventude em espaços concretos. A tríade Estado-sociedade-indivíduos ainda não está completa, mas o enquadramento de construção do tema já não é como fora em 1998. A prova propõe reflexão sobre como os indivíduos jovens podem organizar-se como sociedade para terem protagonismo de participação da/na vida pública. Diferentemente de 1998, mas semelhantemente a 2000, houve solicitação de proposta de intervenção para a questão pública debatida. Diferentemente de 1998 (em que não há vozes sociais), há, nesta edição, como haverá em 2000, a presença de vozes da juventude na construção do tema. 
Figura 4 - Prova de redação do ENEM do ano de 1999

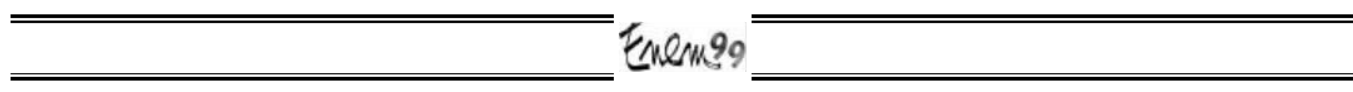

\section{REDAÇĀo}

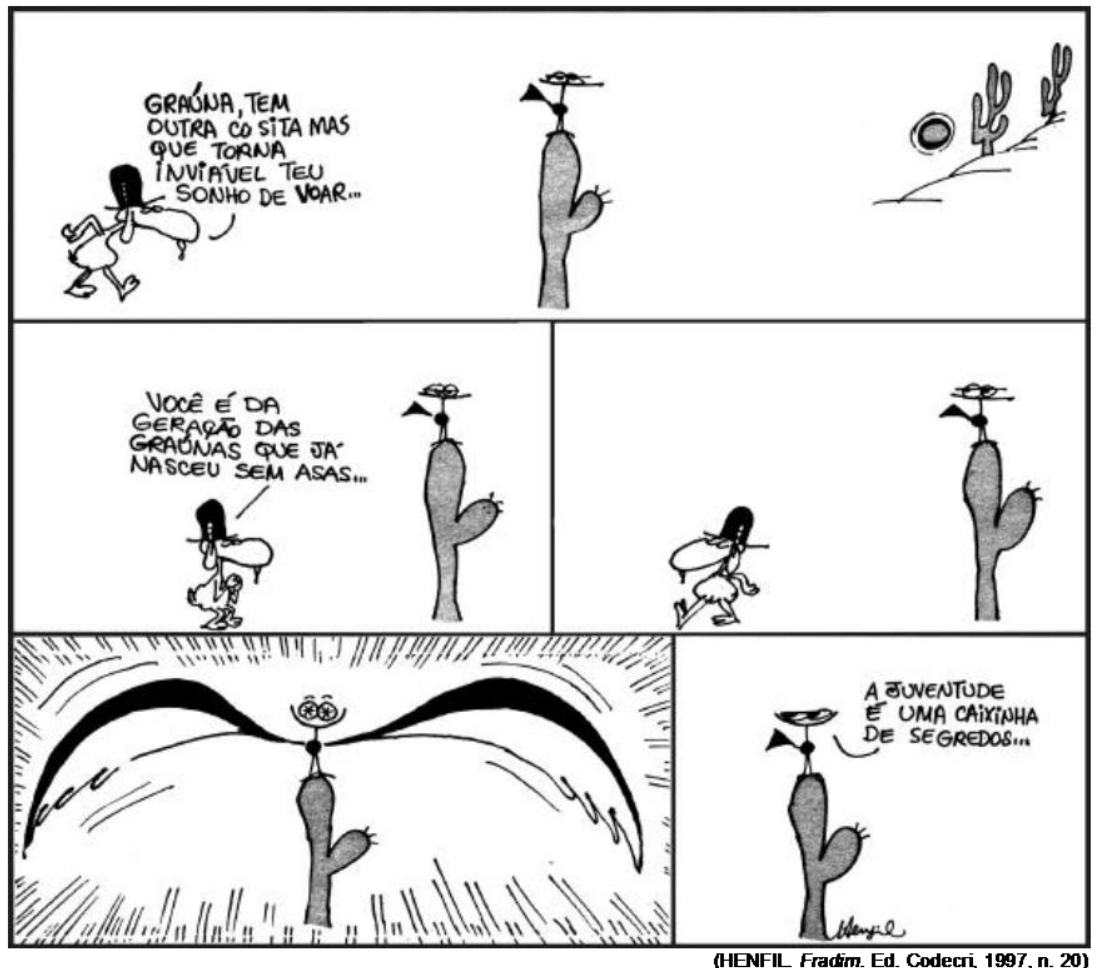

O encontro "Vem ser cidadāo" reuniu 380 jovens de 13 Estados, em Faxinal do Céu (PR). Eles foram tracar experiências sobre o chamado protagonismo juvenil.

O termo pode até parecer fio, mas essas duas palavas significam que o jovem nāo precisa de adulto para encontrar o seu tugar e a sua forma de intervir na sociedade. Ele pode ser pratagonista.

(Adaptado de] Para quem se revolta e quer agir", Folha de $S$. Pauto, 16/1 1/1998)

Depoimentos de jovens participantes do encontro:
- Eu não sinto vergorha de ser brasileiro. Eu sinto mujo orgutho Mas eu sinto vergonha por existirem mudas pessoas acomodadas. A realidade está nua e crua. (...) Tem de parar com o comodismo. Näo dá para passar e ver uma crianca na na e achar que näo é problema SeU. (E.M.O.S., 18 anos, Minas Gerais)

- A maior dica é querer fazer. Se vocé é acomodado, fica esperando cair no colo, não vaj acontecer nada. Existe mula coisa para fazer. Mas primeiro voce precisa se interessar. (C.S.Jr., 16 anos, Paraná)

- Ser cidadáo nāo é só conhecer os seus direitos. É participar, ser dinâmico na sua escola, no seu bairo. (HA., 19 anos, Amazonas)

(Depoimentos extraidos de "Para quem se revolla e quer agi", Fotha de S. Paub, 16/11/1998)

Com base na kitura dos quadrinhos e depoimentos, redifa un texto em prosa, do tipo dissertitivo-argumentativo, sobre o tema: Cidadania e participacāo social.

Ao desemvolver o tema proposto, procure utilizar os conhecimentos adquiridos ao longo de sua formaçäo. Depois de selecionar, organizar e relacionar os argumentos, fatos e opiniōes apresentados em defesa de seu pontb de vista, elabore uma proposta de açāo social.

A redaçāo deveŕ ser apresentada a tinta na cor azll ou preta e deservolvida na folha grampeada ao Cartāo-Resposta. Você poderá utilizar a úlime página deste Cademo de Questōes para rascunho.

É inegável um salto qualitativo na construção dos temas da prova de redação do ENEM de 1998 a 2000 vis-à-vis a presença de elementos para a promoção do debate sobre 
questões públicas dentro de um enquadre interacional melhor delineado. Isso só foi possível porque a prova caminhou no sentido de evidenciar a tríade Estado-sociedadeindivíduos, chegando, inclusive, na edição de 2000, à proposição de um conceito para discussão. De um tema mais genérico, que não salientava vozes sociais voltadas para um fato ou problema concreto, em 1998, chegou-se a um recorte temático mais claro ("Cidadania e participação social"), em que um fato específico - o encontro Vem ser cidadão - incentiva a reflexão, a ser feita por escrito pelo/a candidato/a, sobre a necessidade do protagonismo juvenil, reflexão esta pautada também nas/pelas vozes de outros/as jovens que afirmam a necessidade de a juventude não ser feita de indivíduos apáticos, mas de indivíduos que buscam a ação e, por meio dela, inserção social cidadã (o que abriria possibilidade para inferir-se, embora isso não seja afirmado na prova, ação por meio de participação em alguma entidade da sociedade civil); para, no ano seguinte, em 2000, a construção do recorte temático ser melhor delineado ("Direitos da criança e do adolescente: como enfrentar esse desafio nacional?"), justamente porque a tríade Estado-sociedade-indivíduo fica completa: a voz do Estado é apresentada; na imprensa, tem-se acesso à voz do indivíduo desprovido do direito, que vive o problema-chave do exame; tem-se acesso a uma voz analítica que apresenta um conceito que perpassava toda a sociedade então, infância marginal.

Ao observarmos as três primeiras edições da prova de redação do ENEM, uma pergunta parece inevitável: se, segundo informa Bakhtin/Volochinov (2004), a pesquisa sobre tema (seja de uma palavra ou de um texto) deve levar em consideração a significação contextual desta palavra ou do texto em determinadas condições de enunciação, que conceito passou a integrar a prova de redação do ENEM do ano 2000, e que não estava previsto em suas duas primeiras edições, que fortaleceu a contextualização histórica do problema sob discussão?

\subsection{AS PROVAS DE REDAÇÃO DO ENEM DE 2000 E 2005: EXERCÍCIOS DE REFLEXÃO SOBRE POLÍTICAS PÚBLICAS PARA A INFÂNCIA E A JUVENTUDE NO BRASIL}

O conceito que passou a integrar a prova de redação do ENEM do ano 2000 foi o conceito de política pública. A partir da edição de 2000, a prova de redação do ENEM vem sendo, ora mais, ora menos enfaticamente, tematicamente estruturada a levar o/a candidato/a a discutir uma política pública por meio de um recurso pedagógico deste conceito, a saber, o ciclo de política pública (SECCHI, 2014), tornando-se ela, dessa forma, um exercício de reflexão sobre casos concretos do conceito. Desde então, ela tem caminhado para a promoção de discussão de políticas públicas no Brasil, podendo, inclusive, dialogar com experiências internacionais (como foi, por exemplo, a edição de 2014), uma vez que, no bojo de sua elaboração, pressupõem uma imersão do candidato no universo sócio-político que determina as diretrizes para a implantação de políticas públicas, ainda que isso não seja expresso de forma sistematizada.

Segundo Secchi (2014, p. 11), política pública é um conceito abstrato, materializado por meio de diferentes instrumentos não havendo consenso em torno de sua definição. 
Além disso, as políticas públicas podem ter caráter temático específico ou transversal. Há políticas públicas no campo da assistência social, no campo do acesso à moradia, na educação, na saúde, no campo dos direitos da infância e da juventude, conforme foram abordados nas edições de 2000, 2005 e 2013 do ENEM.

As políticas públicas podem tomar forma de Programas, como o programa Minha Casa, Minha vida, de construção de moradias populares do Governo Federal; podem também tomar forma de Campanhas, das quais um exemplo recorrente são as Campanhas do Agasalho (do governo estadual paulista, por exemplo). Sob o ângulo especificamente legal, podem dar-se sob a forma de Resolução, como a Resolução $n^{\circ}$ 163/2014 do Conselho Nacional da Criança e do Adolescente (CONANDA); ou ainda, sob a forma de Leis. Nesta modalidade, a política pública educacional mais importante é a Lei 13.005, de junho de 2014, que institui o Plano Nacional de Educação (PNE) 20142024.

Em sentido lato, política pública, ainda segundo Secchi (2014, p. 1-2), tem como definição geral:

\footnotetext{
são diretrizes elaboradas para enfrentar um problema público, isto é, o motivo para o estabelecimento de uma política pública é o tratamento ou resolução de um problema coletivamente relevante.

tratam do conteúdo concreto e do conteúdo simbólico de decisões políticas, e do processo de construção e atuação dessas decisões.
}

As políticas públicas são todas as ações de Estado que visam a sanar alguma situação que é entendida como um problema público afetando uma determinada coletividade. Ser "coletivamente relevante", para um problema público, é o primeiro passo para a construção da política, uma vez que a identificação do problema não deixa de ser a construção de um olhar sobre a realidade social. E, por essa razão, ela está sujeita aos - ou é resultado direto dos - interesses e disputas de forças políticas tidas como legitimadas a identificar (ou ignorar) problemas e produzir políticas para eles.

Em termos pedagógicos, elas podem ser pensadas sob o formato de ciclos. Ainda de acordo com Secchi (2014, p. 44), “o ciclo de uma política pública constitui um esquema de visualização e interpretação que a organiza em fases sequenciais e interdependentes". Esse ciclo contém sete fases principais que podem ser visualizadas no esquema apresentado pela Figura 5, na página seguinte.

Em linhas gerais, o que são cada uma das etapas do ciclo de políticas públicas, conforme expõe Secchi (2014)? A Identificação do problema diz respeito à percepção, por uma coletividade, de um problema público. Ele é a diferença entre como é a realidade pública e como se deseja que ela possa ser. A Formação da agenda, por sua vez, é o conjunto de problemas entendidos como relevantes. A agenda pode ser política (problemas ou temas que a comunidade política entende como merecedor de intervenção pública); formal ou institucional (os problemas ou temas que o poder público já decidiu que irá enfrentar); agenda da mídia: são os problemas e temas que recebem atenção dos meios de comunicação. Se voltarmos ao tema da edição de 2000, perceberemos tratar-se de proposta de discussão sobre a formação de agenda de proteção e promoção dos direitos da criança e do adolescente. 
Figura 5 - Ciclo de políticas públicas segundo Secchi (2014)

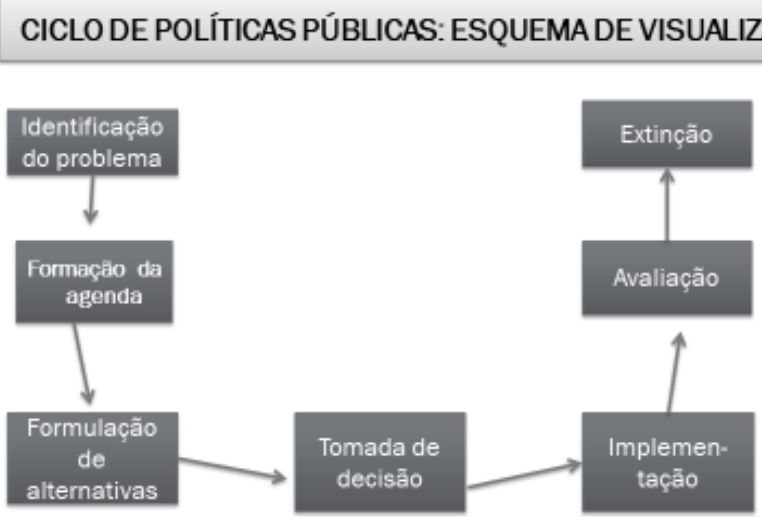

Fonte: Secchi (2014).

A Formulação de alternativas diz respeito ao momento da elaboração de métodos, programas, estratégias ou ações para se alcançar determinados objetivos. A Tomada de decisão é a mobilização para a execução da política. Já a Implementação é a conversão das intenções em ações por meio de instrumentos de política pública: dentre outros, por incentivo fiscal; por aplicação de uma Lei; por legalização ou desregulamentação (como foi o tema de 2014, sobre proibição, ou não, pelo Estado, da publicidade infantil no Brasil). A Avaliação é quando o processo de implementação e o desempenho da política pública são examinados com o objetivo de se conhecer melhor o estado da política e o nível de redução do problema que a motivou (como foi o tema de 2013, sobre os efeitos da Lei Seca, promulgada no Brasil em 2008; e como foi em 2015, que indagava avaliação da Lei Maria da Penha, de 2006). Por fim, a Extinção é a última fase do ciclo de política pública: quando o problema é resolvido; ou quando os problemas de implementação são insuperáveis ou quando ela se torna inútil pelo esvaziamento do problema.

Aqui encontra-se o coração da proposta de articulação teórica que proponho neste trabalho, combinar a visada bakhtiniana sobre tema na língua com a perspectiva do ciclo de políticas públicas. Vimos que as provas de 1998 e 1999 não expunham a diversidade de vozes sociais na construção do tema, não havendo, até então, o triângulo Estadosociedade-indivíduo como eixo organizador da construção temática. Em 2000, porém, além da tríade, propõe-se ao/à candidato/a que, ao refletir sobre "direitos da criança e do adolescente: como enfrentar esse desafio nacional"?, que ele/ela esboce uma agenda de políticas públicas que assegurem direitos da criança e do adolescente. Vamos comparar a construção do tema da prova de 2000, "Direitos da criança e do adolescente: como enfrentar esse desafio nacional?", com a construção da de 2005, "O trabalho infantil na realidade brasileira".

A construção do tema da prova de 2000 apresentava, como já visto, a perspectiva de diferentes atores acerca de um problema público identificado na própria prova como um conceito, a infância marginal. Estar sob o formato de indagação, "como enfrentar esse desafio nacional?", indica, no ciclo de políticas públicas, que aquela prova propunha 
diálogo de formação de agenda. Do porquê disso: a formação de agenda pode se dar em três dimensões, a formação de uma agenda política, que diz respeito a como a comunidade política entende um problema como relevante; a formação de uma agenda formal/institucional, que se caracteriza como o poder público já decidiu de que forma irá enfrentar um problema; e a formação da agenda da mídia, que diz respeito a como os meios de comunicação dão atenção a um problema. A indagação do título é uma indagação sobre qual/quais agendas poderia(m) ser formada(s) no combate ao problema identificado. Os textos motivadores da prova embasam reflexão acerca desse desafio. A própria prova realiza a identificação do problema, portanto. Falta uma agenda específica, porém, para solucioná-lo, que é o que o exame parece solicitar. Vejamos: a demanda por uma agenda política é apresentada na voz do garoto A.J., de 13 anos, ao falar sobre seu trabalho em semáforos. A agenda de mídia, que também detecta o abandono da infância e da adolescência na ordem do dia, está representada pela charge de Angeli. Por outro lado, embora a agenda institucional - ou melhor, um princípio dela - esteja presente, por meio do Art. 227 da Constituição Federal (CF) de 1988, que prevê a proteção à infância como dever do Estado, ainda assim a agenda institucional não se faz presente por meio de seu instrumento precípuo: o Estatuto da Criança e do Adolescente (ECA).

Por isso, a prova de 2000 foi mais uma prova sobre a formação de agenda possível do que uma construção temática que direcionasse o/a candidato/a pensar implementação de alternativas de uma agenda já consolidada. A construção do tema com esse enfoque, de formulação de alternativas a partir de uma agenda, aconteceu na edição de 2005, como se pode observar na Figura 6 a seguir.

Já em uma primeira leitura de toda a prova de 2005, é possível perceber que a tríade Estado-sociedade-indivíduo molda o assunto "infância e adolescência no Brasil", constituindo a construção do tema "O trabalho infantil na realidade brasileira". A tríade também se manifesta nos textos motivadores. O primeiro é um texto multimodal, publicado no ano anterior no jornal $O$ Globo, mas a fonte é o Instituto Brasileiro de Geografia e Estatística (IBGE). Fornece o quantitativo total de crianças que trabalham no Brasil e, além disso, o quantitativo e o percentual deste total em cada região brasileira. É um diagnóstico geopolítico claro do trabalho infantil no país. Por estar em posição superior na página, domina o campo visual para leitura.

Abaixo dele, e simetricamente dispostos, estão os textos 2 e 3 . O texto 2 analisa o quadro ilustrado pelo texto 1 . Consiste em um fragmento de artigo de opinião, publicado em um jornal do nordeste - o Diário de Natal -, região com maior incidência de trabalho infantil no país, segundo o tex to 1, no ano 2000 (coincidentemente, publicado no mesmo ano da última edição em que a prova de redação do ENEM tratou de infância e adolescência). Nele, o autor associa o trabalho infantil ao abandono pelo Estado e por famílias. Há um diálogo com a prova de 2000, quando a Constituição Federal havia sido invocada para marcar o dever do Estado e das famílias de não abandono. Já o texto 3 consiste em fragmento de um artigo de opinião ${ }^{5}$ do professor Joel B. Marin. O artigo resulta da tese de doutorado do autor, sobre trabalho infantil, tendo sido publicado no site da Pró-Reitoria de Extensão e Cultura da Universidade Federal de Goiás (Proec-UFG). O

\footnotetext{
${ }^{5} \mathrm{O}$ artigo completo está disponível em: <http://www.proec.ufg.br/revista_ufg/agro/K16_infantil.html>. Acesso em: 15 maio 2017. 
texto introduz elementos que tornam mais complexo o debate sobre o trabalho infantil no país: 1) trata do trabalho infantil no campo, ampliando o alcance do tema para além do espaço urbano. Cumpre lembrar que, salvo este texto, em nenhuma das demais edições da redação do ENEM sobre o assunto infância e adolescência a especificidade da criança/jovem do campo foi abordada; 2) o texto reporta o ponto de vista de famílias que valorizam o trabalho infantil (que é resultado do abandono social) como forma de proteção social.

Figura 6 - Prova de redação do ENEM do ano de 2005

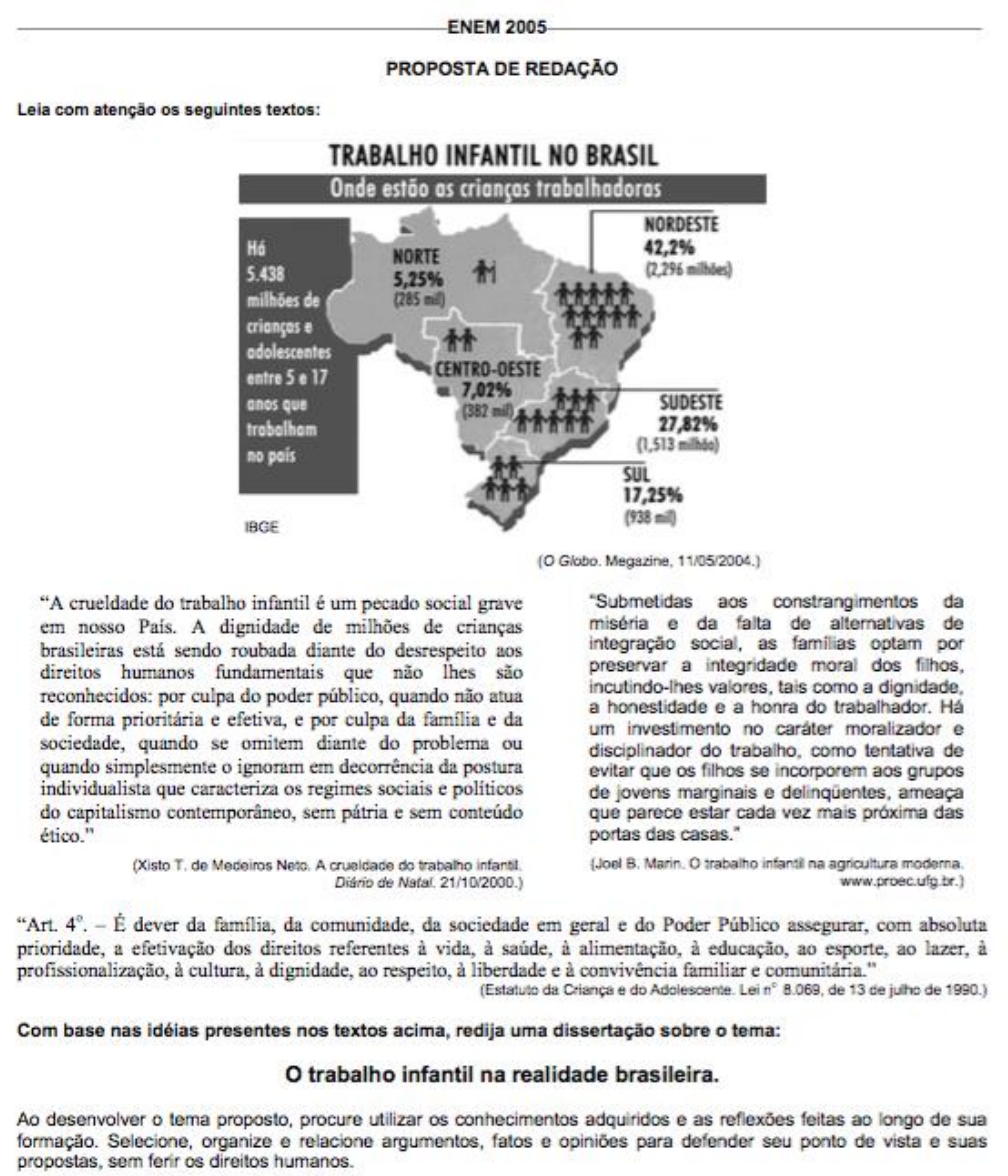

Fonte: ENEM 2005.

Ainda sobre a prova de 2005, o diálogo desta com a prova de 2000 reforça-se (e ao mesmo tempo revela como a edição de 2005 é mais orgânica vis à vis a discussão sobre políticas públicas) com o texto motivador 4. A vocalização do Estado não se dá pela Constituição Federal (CF), mas agora pelo fragmento (o Art. $4^{\circ}$ ) do documento jurídico específico resultante da elaboração da agenda institucional de proteção da infância e da adolescência, o Estatuto da Criança e do Adolescente (ECA), de 1990. Não obstante o Art. $4^{\circ}$ do ECA e o Art. 227 da CF tratem do dever do Estado e das famílias de promover proteção e direitos à criança e ao adolescente - excluindo-se, deste rol, evidentemente, o trabalho -, a presença do ECA na prova de 2005 leva-nos a ler que a agenda institucional, que parece coincidir com a agenda política e a agenda de mídia representadas em outros 
textos motivadores, é a de combate ao trabalho infantil no país. É por isso que, enquanto a prova de 2000 propõe um debate, dentro do ciclo de políticas públicas, na formação de agenda, a prova de 2005 propõe a formulação de alternativas para uma agenda específica: o trabalho infantil existe, é reconhecido, em sua complexidade, nas agendas política e formal e deve ser combatido.

\subsection{A PROVA DE 2014: TOMADA DE DECISÃO E IMPLEMENTAÇÃO}

Se recobramos Bakhtin/Volochinov (2004) uma vez mais, observamos que o conceito de tema, para o autor, constitui o "estágio superior real da capacidade linguística de significar" [grifos do autor]. Estudar o tema de uma palavra ou enunciado é estudar a "investigação contextual de uma dada palavra nas condições de uma enunciação concreta" (BAKHTIN/VOLOCHINOV, 2004, p. 131). Até aqui tentamos demonstrar que foi tornando-se evidente que as construções temáticas sobre infância e adolescência/juventude na prova de redação do ENEM desenvolveram-se no sentido de construir temas apresentando instrumentos de políticas públicas para a discussão de diferentes problemas públicos relativos à infância e à juventude no Brasil. Se em 1999 o tema "Cidadania e participação social", oportunidade em que a prova tratou da necessidade de ativismo social pela juventude, ainda não se circunscrevia ao conceito de política pública, em 2000, com o tema "Direitos da criança e do adolescente: como enfrentar esse desafio nacional?", os conceitos de política pública e de ciclo de políticas públicas são introduzidos no exame, na medida em que a proposta indaga sobre como formar uma agenda em torno da questão; em 2005, quando novamente a temática sobre infância e adolescência/juventude, a saber, "O trabalho infantil na realidade brasileira" volta ao exame, observa-se a manutenção do conceito de ciclo de política pública; observa-se, particularmente, que o exame foi construído já com base em uma agenda predeterminada, a do combate ao trabalho infantil, ficando a cargo do/a candidato/a promover uma discussão de formulação de alternativas.

Com a prova de redação do ENEM bastante assente nas relações entre Estadosociedade-indivíduos e como políticas públicas devem atuar na promoção dos direitos humanos, a construção do tema na edição de $2014^{6}$ reitera a maneira como o problema público é estruturado e como a interlocução é solicitada: 
Figura 7 - Prova de redação do ENEM do ano de 2014

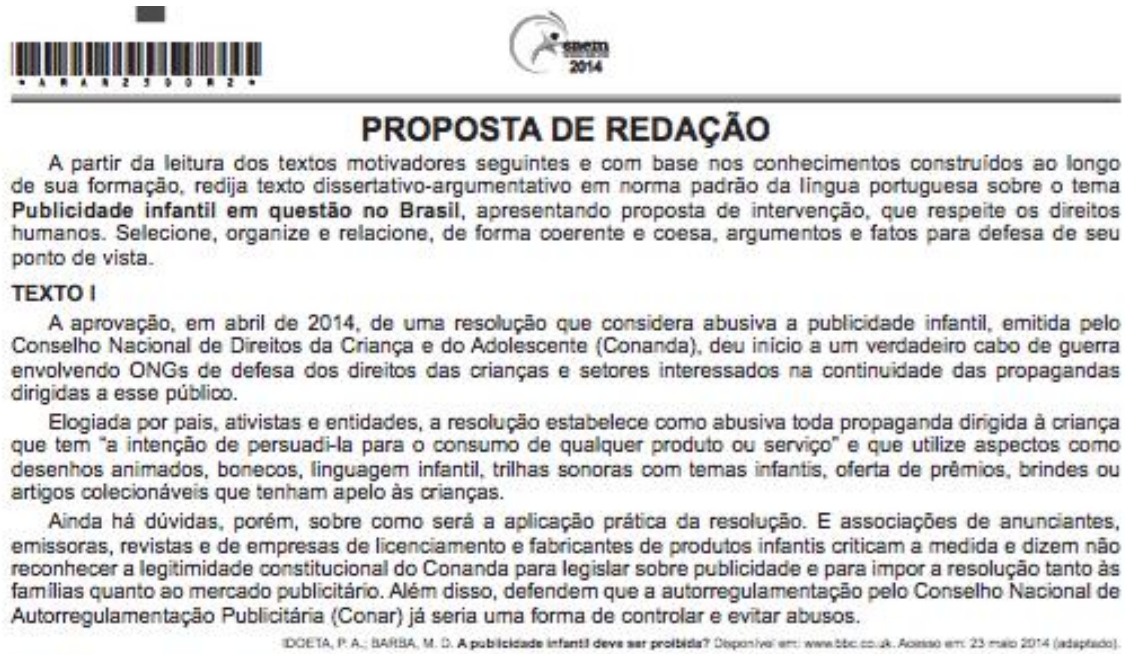

TEXTO ॥

A PUBLICIDADE PARA CRIANÇAS NO MUNDO

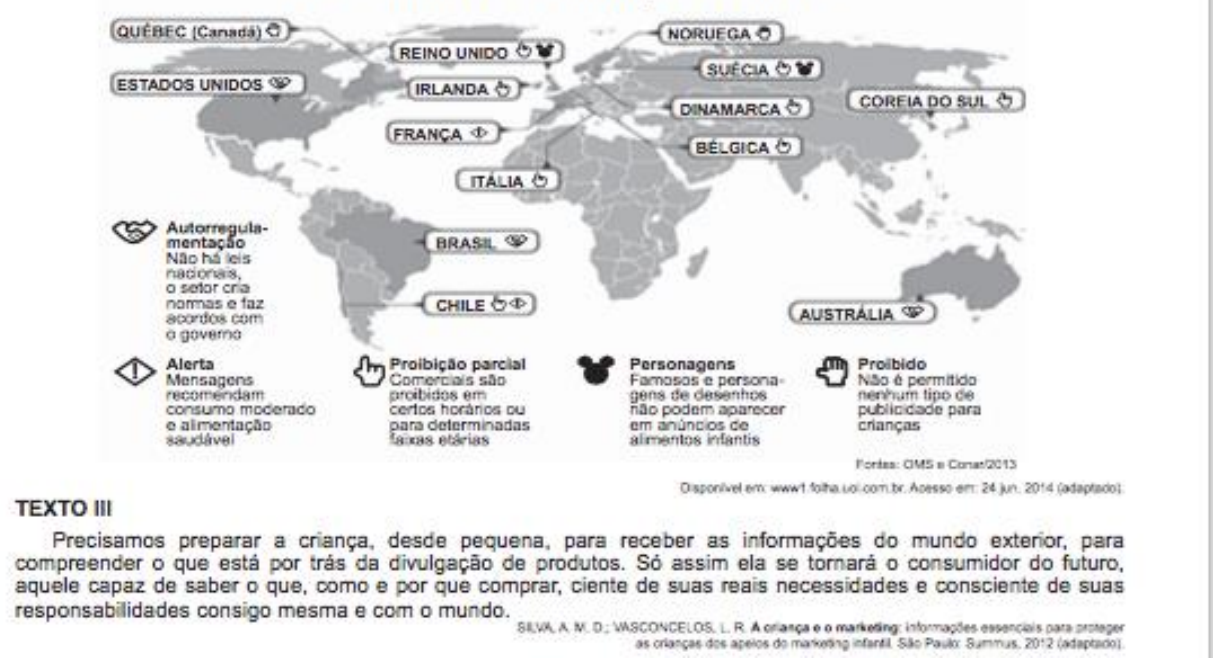

Fonte: ENEM 2014.

Com o tema nomeado "Publicidade infantil em questão no Brasil", a prova de 2014 apresentou três textos motivadores. São menos textos do que as demais edições com recorte semelhante. Porém, a tríade Estado-indivíduo-sociedade se faz presente, havendo, inclusive, uma novidade. O texto 1 é o fragmento de uma reportagem da BBC, em que são apresentados os pontos de vista de dois vértices do triângulo: de um lado, o do Estado; do outro, o do terceiro setor e o do setor privado (ambos pertencendo ao vértice "sociedade", não obstante seus pontos de vista sejam diferentes). Da parte do Estado, informa o texto sobre a publicação de uma resolução pelo Conselho Nacional de Direitos da Criança e do Adolescente (Conanda) ${ }^{7}$, que julga abusiva a publicidade infantil no país. Lembremo-nos: em 2000, quando da primeira aparição de um texto do Estado na prova, constava o Art. 227 da Constituição Federal, que preconiza como dever da família, do

\footnotetext{
${ }^{7}$ O Conanda foi criado criado pela Lei 8242/1991. Segundo o Art. $1^{\text {o }}, \S 1^{\text {o }}$, o Conanda "integra o conjunto de atribuições da Presidência da República".

Disponível em: < http://www.planalto.gov.br/ccivil_03/leis/L8242.htm>. Acesso em: 30 maio 2017. 
Estado e da sociedade a proteção à infância; em 2005, constava o Art. $4^{\circ}$ do Estatuto da Criança e do Adolescente (ECA), que preconiza também como dever destes mesmos atores assegurar à criança e ao adolescente direitos civis e sociais. No mesmo texto 1 da prova de 2014, consta o Conanda; mas consta também que, ao poder público, no campo da publicidade, não cabe promover a proteção da infância, mas cabe ao setor empresarial, mediante o Conselho Nacional de Autorregulamentação Publicitária (Conar), conselho este que se opõe à atribuição legal prevista ao Conanda. No texto, o Conar advoga em defesa dos interesses da família e do próprio mercado. Entre todas as edições da redação do ENEM sobre o assunto infância e adolescência, essa foi a de exposição mais explícita entre interesses privados $v s$ proteção contra a perda de direitos por este segmento social.

A novidade desta edição com relação àquelas que discutiram infância e adolescência é a presença da discussão do tema em outros países, cabendo ao/à candidata/o discutir a inserção internacional do Brasil neste aspecto. Observa-se na prova de 2014 a repetição de um padrão presente desde a prova de 1999, a presença de texto multimodal entre os textos motivadores. O texto 2 é um mapa mundi apresentado como recorte geopolítico: nações deliberadamente liberais, do ponto de vista econômico, como EUA e Austrália, adotam ou sistema de autorregulamentação, ou sistema de proibição parcial como Coreia do Sul, ao passo que países com maior presença do Estado na regulação econômica, ou países com o Estado de Bem-Estar Social, ou adotam proibição parcial ou, em um caso, o da Noruega, a proibição total. Cumpre observar que o que está em questão no Brasil, fundamentalmente, é o embate entre a proteção à infância vs os ganhos das empresas, dado o tamanho do mercado consumidor em potencial no país ${ }^{8}$. Reside neste embate a extrema relevância da discussão empreendida pela prova. No assunto infância/adolescência, a construção dos temas sempre revelou-se no sentido de expor conflitos e necessidades de avanços quanto à salvaguarda e/ou a promoção de direitos de crianças e adolescentes/juventude. Novamente, agora em escala internacional, os vértices "Estado" e "sociedade" estão representados neste texto.

O texto 3, por sua vez, apresenta os vértices "sociedade" (por meio das famílias) e "indivíduo". Vocaliza os anseios de indivíduos por meio de um conceito, consumidor do futuro. Repete-se, assim, procedimento da edição de 2000, em que havia a elaboração de um conceito (infância marginal). Como se pode observar, na prova de 2014, os textos motivadores e a interlocução que promovem são reveladores de que esta edição solicitou às/aos candidatas/os que pensassem, dentro do ciclo de políticas públicas, em uma tomada de decisão e na implementação de ações: regulamentar ou não regulamentar? Totalmente? Parcialmente? Se sim, por meio de quais instrumentos a serem implementados?

\footnotetext{
${ }^{8}$ Esse texto começou a ser pensado a partir de um curso de extensão por mim ministrado, "A prova de redação do ENEM: Políticas Públicas em Direitos Humanos", na Faculdade de Letras da Universidade Federal de Goiás (UFG), em maio de 2016. A observação acerca do tamanho do mercado consumidor em potencial no Brasil - observação, diga-se de passagem, muito apropriada - foi feita pela cursista Stefania Vieira de Melo, graduada e mestre em História e professora da rede particular de Goiânia.
} 
As construções temáticas sobre infância e adolescência/juventude na prova de redação do ENEM, em cada edição em que o assunto "infância e adolescência" foi tematicamente construído - nos anos de 1999, 2000, 2005 e 2014 -, desenvolveram-se no sentido de promover discussão sobre políticas públicas de proteção a este segmento social, tendo como perspectiva o alcance nacional destas políticas. Afinal, todas elas, como pudemos observar, foram construídas em torno de um eixo de relações sociais e embates entre atores característicos de democracias liberais como o Brasil, que se propõem como Estado Democrático de Direito. Esse eixo foi por nós representado pelo triângulo Estado-sociedade-indivíduo, em que cada um deste conjunto de atores configura um vértice do triângulo. Políticas públicas são todas as ações, instrumentos e aplicações de recursos por parte do Estado (se se adotar uma visão estadocêntrica do conceito) ou por parte de diferentes atores sociais, como ONGs ou associações de empresas (se se adotar uma visão multicêntrica do conceito), com vistas à resolução de um problema coletivamente entendido como relevante por uma dada comunidade. A primeira afirmação definidora da prova de redação do ENEM como exame sobre políticas públicas se dá em razão de todas as edições analisadas apresentarem um problema público vivenciado em, ou representativo de, todo o território nacional, e como os diferentes atores apresentam soluções para eles.

Além disso, a segunda afirmação que define a prova de redação do ENEM como um locus de discussão sobre políticas públicas consiste no fato de que nas edições analisadas não é solicitada apenas a implementação de instrumentos de políticas públicas. $\mathrm{Na}$ verdade, diferentes etapas do ciclo de políticas públicas foram convocadas pelo exame na construção temática das edições analisadas. Conceito de cunho operacional e didático, o ciclo de políticas consiste em todas as fases de construção de uma ação contra um problema público. É claro que, porque a prova solicita proposta de intervenção pelo/a candidato/a, infere-se que proposta seria a formulação de alternativas. No entanto, observou-se mais: o tema da edição de 2000 era mais voltado para a formação de agenda: "como enfrentar o desafio nacional de defesa de direitos da criança e do adolescente?", pergunta a prova; o da de 2005, solicita a formulação de alternativas, uma vez que a agenda é apresentada no nome do tema, "O trabalho infantil na realidade brasileira"; o da de 2014, por fim, indaga sobre por qual tomada de decisão o candidato deve optar: controle total, controle parcial ou não controle da publicidade infantil no Brasil contemporâneo.

Maior evento institucionalizado de produção textual simultânea do Brasil, a prova de redação do ENEM é importante não apenas por sua aplicação em larga escala, mas, sobretudo, por oportunizar a milhares de jovens, e, indiretamente, à própria população, a discussão de problemas públicos que não necessariamente compõem a agenda de mídia. Ora, se "o tema da enunciação é concreto, tão concreto como o instante histórico ao qual ela pertence" (BAKHTIN/VOLOCHINOV, 2004, p. 129), a análise apontou que a prova de redação do ENEM empenha-se em mostrar o "instante histórico" sob o viés de agendas necessárias e que não aquela geralmente mais conhecida, a agenda de mídia. Nas edições em questão, as análises mostraram um enfoque da agenda política e da agenda 
institucional, o Estado voltando-se para a discussão e/ou solução de problemas que podem ferir direitos da infância e da adolescência. Para nós, professoras/es de Língua Portuguesa, a prova de redação do ENEM pode ser um incentivo ao ensino de leitura e produção textual por meio de projetos interdisciplinares com nossos colegas de História, Sociologia, Geografia ou Filosofia na/para a discussão de políticas públicas no ensino de língua. Um ensino de língua conjugado com reflexão sobre direitos pode ser uma combinação saudável para a promoção da democracia.

\section{REFERÊNCIAS}

BAKHTIN, M./VOLOSHINOV, V. M. Marxismo e filosofia da linguagem. São Paulo: Editora Hucitec, 2004.

BAKHTIN, M. Os gêneros do discurso. In: Estética da criação verbal. São Paulo: Martins Fontes, 2000. p. 279-326.

BRASIL. Ministério da Educação. Portaria MEC nº 438, de 28 de maio de 1998. Brasília, 1998. Disponível em: <http://www.crmariocovas.sp.gov.br/pdf/diretrizes_p0178-0181_c.pdf>. Acesso em 26 jun. 2017.

Ministério da Educação. ENEM, documento básico. Brasília, 1999. Disponível em: <http://www.dominiopublico.gov.br/download/texto/me000115.pdf>. Acesso em: 26 jun. 2017.

Ministério da Educação. Portaria $n^{o} 111$, de 04 de dezembro de 2002. Brasília, 2002.Disponível em: 〈http://download.inep.gov.br/educacao_basica/encceja/legistacao/2002/portaria111.pdf〉. Acesso em: 26 jun. 2017.

Ministério da Educação. Portaria no. Portaria no 07, de 19 de janeiro de 2006. Brasília, 2006. Disponível em: < http://www.diariodasleis.com.br/busca/exibelink.php?numlink=1-221-29-2006-01-197>. Acesso em: 26 jun. 2017.

Ministério da Educação. Proposta: unificação dos processos seletivos das Instituições Federais de Ensino Superior a partir da reestruturação do Exame Nacional do Ensino Médio (Enem) Brasília, 2009. Disponível em: < http://download.inep.gov.br/download/imprensa/Andifes_Proposta_InepMEC.pdf >. Acesso em: 27 jun. 2017.

Ministério da Educação. A redação no ENEM 2013: guia do participante. Brasília: INEP, 2013.

OLIVEIRA, J. de P. Objetivos do ENEM e os desdobramentos a partir do seu uso como exame de acesso à educação superior. In: 36a REUNIÃO NACIONAL DA ANPED, 1, 2013, Goiânia. Anais... Goiânia: UFG, 2013. Disponível em:

<http://36reuniao.anped.org.br/pdfs_posteres_aprovados/gt11_posteres_aprovados/gt11_3119_texto.pdf >. Acesso em: 15 maio 2017.

PORTELA, P.H.G. Direito Internacional público e privado. 5a edição. Salvador: Editora Jus Podium, 2013.

QUINALIA, C. L. et. al. (2013). Política pública de educação uma análise do ENEM: exame nacional do ensino médio no Distrito Federal. Universitas/JUS, v. 24, n. 1, p. 61-78, 2013. Disponível em:

<http://www.publicacoesacademicas.uniceub.br/index.php/jus/article/viewFile/2259/1891>. Acesso em: 15 maio 2017.

REZENDE, R. C. (2014). A prova de redação do ENEM e o ensino de Língua Portuguesa no Ensino Médio. Palestra ministrada na Universidade Estadual de Feira de Santana (UEFS), Bahia, Brasil, em 11 de agosto de 2014. Inédito.

SECCHI, L. Políticas públicas: conceitos, esquemas de análise, casos práticos. São Paulo: CENGAGE Learning, 2014.

Recebido em: 22/08/17. Aprovado em: 06/06/18.

REZENDE, Renato Cabral. Políticas públicas como tema de produção textual: uma análise bakhtiniana de cinco edições da prova de redação do ENEM. Linguagem em (Dis)curso - LemD, Tubarão, SC, v. 18, n. 3, p. 485-506, set./dez. 2018. 
Title: Public policies as the theme for text production: a bakhtinian analysis of five editions of ENEM composition exam

Author: Renato Cabral Rezende

Abstract: This work aims at analyzing the theme construction of five editions of ENEM composition exam. These editions had as its theme object (BAKHTIN, 2000) infancy and/or youth. We intend to discuss the thematic construction of the composition exam based on the concept of theme, according to Bakhtin (2000) and Bakhtin/Volochinov (2004), and the concepts of public policies and cycle of public policies, according to Secchi (2014). The analysis has shown a focus on how State can debate problems that might interfere in the rights of infancy and youth. We conclude by restating the need of understanding the ENEM composition exam as an inducement to the teaching process of texts reading and texts production bias interdisciplinary projects which involve the discussion of public policies.

Key-words: Theme. Text production. Public policies. ENEM.

Título: Políticas públicas como tema de producción textual: un análisis basado en Bajtín de cinco ediciones de la prueba de redacción del ENEM

Autor: Renato Cabral Rezende

Resumen: Este trabajo tiene por objetivo analizar la construcción de tema de cinco ediciones de la prueba de redacción del ENEM, que tuvieron como objeto de sentido (BAKHTIN, 2000) infancia y/o juventud. Almeja discutir construcción temática de la prueba de redacción desde la relación entre el concepto de tema, de acuerdo con Bajtín (2000) y Bajtín/Volochinov (2004), y los conceptos de políticas públicas y ciclo de políticas públicas, del campo de la administración pública, basado en Secchi (2014). El análisis muestra un enfoque sobre cómo el Estado se puede volver para la discusión y/o solución de problemas posibles de herir derechos de la infancia y de adolescencia. Concluye reafirmando la necesidad de lectura de la prueba de redacción del ENEM como un incentivo para enseñanza de lectura y producción textual por medio de proyectos interdisciplinares en la o para la discusión de políticas públicas.

Palabras clave: Tema. Producción textual. Políticas públicas. ENEM.

\section{AGRADECIMENTO}

Agradeço à Mariana Sodário Cruz pelos diálogos que me ensinaram e me ensinam sobre políticas públicas e que me orientaram a correlacioná-las com a prova de redação do ENEM. Este trabalho não teria sido possível sem sua interlocução. Eventuais erros que persistam no texto são de minha inteira responsabilidade.

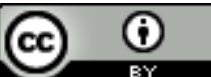

Este texto está licenciado com uma Licença Creative Commons Atribuição 4.0 Internacional.

REZENDE, Renato Cabral. Políticas públicas como tema de produção textual: uma análise bakhtiniana de cinco edições da prova de redação do ENEM. Linguagem em (Dis)curso - LemD, Tubarão, SC, v. 18, n. 3, p. 485-506, set./dez. 2018. 